\title{
Política de la investigación artística
}

\section{Carolina Benavente y Gustavo Celedón, U. de Valparaíso}

En su segundo número, Panambí comienza su periodo de consolidación. Se han incorporado nuevas personas al complejo trabajo de mantener en pie una revista de investigación artística. Samuel Toro, artista sonoro y estudiante del Doctorado en Estudios Interdisciplinarios sobre Pensamiento, Cultura y Sociedad de la Universidad de Valparaíso, como ayudante de edición. Daiana Nascimento dos Santos, investigadora posdoctoral del Centro de Estudios Avanzados de la Universidad de Playa Ancha, como revisora de los artículos en portugués, sumándose a Thomas Rothe, estudiante del Doctorado en Estudios Latinoamericanos de la Universidad de Chile, revisor de los textos en inglés. Pues Panambí pretende contribuir siempre a explorar la multiplicidad de modos en que los conocimientos se generan y circulan por medio de diferentes lenguas, lenguajes, formas, modos, métodos, superficies de inscripción, etc. En cuanto a los idiomas, ciertas aberturas son probables, posibles y necesarias, por su cercanía, su hermandad, su certeza en la aplicación. Por otro lado, con Marcia Martínez, académica de la Escuela de Teatro de la Universidad de Valparaíso y nueva integrante del Consejo Editorial, renovamos a quienes colaboran con nosotros en el seno de la institución universitaria que nos alberga. Presentamos, además, un conjunto de nuevos autores que transitan entre la creación y la investigación, insertos por lo general en la academia, pero no siempre ni tampoco en forma exclusiva.

La confianza de personas e instituciones en un proyecto como Panambi es fundamental, como lo es su apoyo. La actual coyuntura de la investigación artística y también humanista nos ubica en ese espacio concreto de la necesidad de plantear alternativas no sólo a la llamada "producción" de conocimientos, sino también a la definición y comprensión de lo que la misma palabra "conocimiento" quiere decir para el hacer en la academia y en lugares que no son la academia pero que se relacionan igualmente al conocer $\mathrm{o}$ al saber de manera fundamental.

En Chile existe no sólo la inquietud, sino la conformación de grupos de trabajo e instancias de discusión en red que tienen como objetivo instalar en el debate público y proponer a los organismos oficiales la conveniencia de fortalecer la investigación en artes y humanidades. Esto, de acuerdo con necesidades que mal haríamos en llamar internas, pero que podríamos comprender como diferentes a los encapsulamientos que imponen las actuales metodologías de conformación de comités, formulación de proyectos, asignación de recursos o evaluación de tareas, tal como están diseñadas. Sin embargo, para nosotros no se trata simplemente de demandar un espacio más amplio de participación, sino también de 
discutir las nociones en juego de investigación, conocimiento, metodología, procedimiento, objeto, objetivo, redacción, continuidad, etc. Pues es, justamente, la multiplicidad de posibilidades que se inscriben en el ejercicio de la investigación una de las proposiciones vitales de la discusión emanada por las artes y las humanidades en relación a las políticas de investigación y conocimiento.

Las llamadas ciencias duras, lo sabemos, también se ven afectadas por la creciente brecha existente entre las expectativas que despierta la investigación, en cuanto a su aporte al desarrollo del país, y el apoyo concreto que recibe como actividad. Estando vinculada en forma estrecha a la educación, la investigación no se confunde con ella, y sería improcedente seguir limitando su impulso para privilegiar la primera. La preservación, la transmisión y la generación de conocimientos en los más variados ámbitos forman un sistema que es necesario potenciar en todas sus dimensiones y vectores. Constatar la variedad inmensa de las artes en sus modos de crear e investigar, así como de ser creadas e investigadas, nos permite asimilar la complejidad de relaciones que comporta cualquier entramado de conocimiento, especialmente si se traslapa de manera clara con aquello que deja de serlo en forma específica, pues comienza a ser su aplicación estética y poética.

Las artes no reclaman una diferencia esencial respecto de otros ámbitos disciplinarios porque, en el límite, cualquiera de ellos puede derivar en un terreno de aplicabilidad. Pues el llamado "Research \& Development" podría entenderse de forma ampliada, no para reducir las artes a las habituales exigencias comerciales de las actividades que hoy recubre el concepto, sino, por el contrario, para que éstas abarquen amistosamente las técnicas y tecnologías aptas a la satisfacción de necesidades o aspiraciones subjetivas y culturales. Al tener esto en cuenta, la discusión deja de ser puramente disciplinaria o, en el peor de los casos, gremial: versa sobre problemas que atañen al conjunto social, cada vez más compenetrado, cada vez más incitado a conocer, por la globalización operante, pero a la vez condicionado por un proceso de homogeneización fulminante que absorbe todas las experiencias y realidades diversas que precisamente pueden conocerse. Frente a esta homogeneización, el campo artístico manifiesta la divergencia que involucra cualquier saber generado desde singularidades sintientes.

Este número de Panambí busca seguir contribuyendo a la construcción de un espacio en donde las investigaciones artísticas se desplieguen con soltura y seriedad y donde se reflexione sobre las múltiples orientaciones y significaciones que puede en sí tener la investigación artística. Los artículos, tesis, reseñas y trabajos artísticos publicados en esta segunda edición son verdaderos aportes en este sentido. Las contribuciones artísticas de Nemesio Orellana y Angie Saiz dan cuenta de manera concisa, pero nítida, de los procesos de conocimiento que se activan en y frente a la producción artística. Mismos procesos que subyacen a los artículos de Ricardo Mandolini, desde la música, y Mauricio Bravo, desde la escultura, en 
complicidad inteligente y sensible a la vez con la teoría de la complejidad y la crítica foucaultiana de la gubernamentalidad, respectivamente.

El teatro se hace presente, en esta ocasión, por medio de desplazamientos en el tiempo y el espacio, hacia la escena independiente de Buenos Aires en la primera mitad del siglo XX, en el caso de María Fukelman, y hacia la única escuela universitaria en esta disciplina que ha habido en la ciudad de Valdivia, entre los años 1970 y 1976, en el caso del artículo de tesis de Sibila Sotomayor y Angélica San Martín. Similar indagación en la historia y por la memoria ocurre en el estudio que Cristian Galarce y Lucía Di Salvo le dedican a la poética del cantante y compositor brasileño Chico Buarque, así como en la reseña que hace Vanessa Moraes de un documental sobre otro poeta de ese país, Chacal. Y si en este último caso se aborda el contenido de una producción cinematográfica, el artículo de José Miguel Arancibia nos conduce a sospechar de las conexiones mismas entre cine y representación, a partir de una cita de Walter Benjamin y su posible traducción.

El cuerpo se perfila, en esta edición de Panambí, como una presencia destacada, al ser objeto de las contribuciones de Gabriel Cid de García sobre el horror y la desnaturalización de la forma en artes visuales; de Filipe Ceppas sobre el diálogo entre Ana Mendieta y la tradición amerindia, para lo cual recurre a Gilles Deleuze y Jacques Derrida; y de Álvaro Rodríguez-Luévano sobre la dimensión heterotópica de los tatuajes de convictos, tal como han sido realizados, fotografiados, dibujados y editados por los propios tatuadores y por diferentes artistas. Estos textos, en conjunto con los anteriores, refuerzan en nosotros una comprensión del arte como práctica social y cultural compleja, cuyo conocimiento aplicado permite abrir espacios de autonomía a insospechadas diferencias. Agradecemos por ello a todos sus autores. 